\title{
Metacognitive and Metaemotional Training Strategies through the Nine-layer Pyramid Model of Emotional Intelligence
}

https://doi.org/10.3991/ijes.v9i4.26189

\author{
Athanasios Drigas $^{1(\mathbb{凶})}$, Chara Papoutsi ${ }^{1,2}$, Charalabos Skianis ${ }^{2}$ \\ 'National Center for Scientific Research "Demokritos", Athens, Greece \\ ${ }^{2}$ University of the Aegean, Samos, Greece \\ drait.demokritos.gr
}

\begin{abstract}
Emotional intelligence constitutes an important 21st century skill that impacts positively several areas of everyday life. It contains competencies that enhance the ability of other significant skills for self-development. The main purpose of this study is to present the way we can develop and improve our emotional intelligence based on the pyramid model and its nine layers. To achieve this goal, the paper seeks to address the following question: What are the metacognitive and metaemotional skills and strategies that can play a key role in developing, enhancing and improving emotional intelligence? Extensive reference is made to the skills that involved in each layer and have been identified as necessary and should be cultivated by the individual leading gradually to the higher levels of self-actualization and transcendence. Furthermore, we suggest some strategies in each layer that work auxiliary and supportive for the cultivation of the specific skills. Metacognitive and metaemotional skills and strategies are necessary to conquer the levels of emotional intelligence and to apply in a variety of contexts with the aim of developing emotional intelligence and self-improvement.
\end{abstract}

Keywords-emotional intelligence, metacognition, metaemotion, metacognitive abilities, skills, strategies, attention, self-regulation, self-awareness, layered pyramid model

\section{Introduction}

Every day we are overwhelmed by a plethora of emotions, positive and negative ones. We need to be able to pay attention to our emotions, to recognize them, to express them and manage them in the best possible and productive way. As a result, we gain more knowledge about ourselves, about others, we have empathy and increased social skills.

Emotional intelligence is a particularly important psychological concept in the last decade gaining ground in studies and research in many areas of everyday life attracting the attention of scholars, experts, professional teachers, and the public. It is a fact that there is a debate and a disagreement about the definition and the measurement of 
emotional intelligence, and the abilities - skills - characteristics of which it is composed, resulting in the construction of different models. Common to all theories, however, is that statistical research has stated the positive correlation of emotional intelligence with health (psychological and physical one), personal well-being, stress, academic performance, work performance, social relationships, education, and leadership [1-5].

Emotional intelligence (EI) is related to skills and abilities that allow awareness of the emotional state of oneself and others and the ability to use and regulate emotions to positively affect one's performance in all areas of one's life. Emotional intelligence can be defined as a set of abilities and skills that a person must train and develop gradually and hierarchically to reach emotional self-realization [6].

Emotional intelligence is also related to cognition, metacognition and metaemotion. Cognition affects emotions, and emotions in turn shape cognitive processes such as attention, evaluation, problem-solving, perception, memory, learning, and decision making [7]. Metacognition is the ability of individuals to know their own cognitive functions in order to monitor and to control their learning process [8]. Quirk (2006) defines metacognition as "the ability to think about one's thinking and feelings and to predict what others are thinking" [9]. Metacognition in Emotional Intelligence means that an individual perceives his/her emotional skills [10]. Its processes involve emotional-cognitive strategies such as awareness, monitoring, and self-regulation [11] to monitor, evaluate and manage second emotional thoughts that may accompany a primary emotion for a better emotional state and emotional reaction [12] and for the improvement of his personality and this can be an incentive to help other people in this field for better interpersonal and interpersonal interactions. Applying the meta-knowledge to socio-emotional contexts should lead to the opportunity to learn to correct one's emotional errors and to promote the future possibility of a proper response to the situation [13]. Metaemotion is the process of having secondary emotions following a primary one [14] based on how the latter is perceived and it is experienced. It is a set of emotions, thoughts, and cognition about emotions, both of oneself and of others. Mitmansgruber et al. (2009) define metaemotion as emotional reactions to the "emotional self" [15]. According to Wong Ming Yan (2010) the components of metaemotion include awareness, acceptability, communication, causality, manipulation and coaching [14].

Drigas \& Mitsea (2020) presented the core components of metacognition demonstrating the significance of it in learning and in self-knowledge [16]. The creation of the eight pillars of metacognition can be the springboard for the construction of the eight pillars of meta-emotion which is particularly important for achieving learning, self-awareness, social awareness and transcendence:

1. Deep theoretical knowledge about human emotions, their characteristics, and their functionality.

2. Self-awareness and self-evaluation of ourselves (emotions, strengths, weaknesses, thoughts, beliefs, and motives).

3. Self-monitoring our emotional self. Observing our emotional and mental states in real time framework. We become observes of ourselves.

4. Self-regulation. The ability to regulate, to manage, to change and to moderate the emotional and mental states. 
5. Adaption. Having the ability to be flexible in the functional state of emotional skills to adapt in everyday circumstances and life demands.

6. Recognition. Be fully aware of the dimensions of emotions, the real causes the provoke them, their relations, their correlations and to realize and perceive everything that happens around you in emotional, mental, and physical level.

7. Discrimination. The ability to filter and to discern among emotions and emotional situations and to make selections that are positive, optimistic, promising for reaching our goals and for self-development.

8. Mnemosyne (memory in Greek). Become fully aware of yourself, to awake, and to pay attention, internally and externally. To remember your emotional reactions, your emotional skills that are available to you and to apply them in real time.

Emotional intelligence can be learned, cultivated, and mastered through training, interventions, and life experiences and its training is effective and has a positive impact on research participants $[17,18]$. The human brain has plasticity and has also the ability to change and adapt. Practicing and training cognitive and emotional skills leads to the creation of new neural synapses to adopt a new behavior. Neural plasticity has been observed in the key areas of the brain that are involved in the emotional circuitry, and some of the most impressive evidence for brain plasticity have been observed during emotional learning [19]. All these leads to the conclusion that individuals need to adopt additional abilities/skills and training strategies that are included in each level of the pyramid model (Figure 1) to master the skills of the pyramid, to develop emotional intelligence for the creation of a better self and succeed in self-actualization and transcendence.

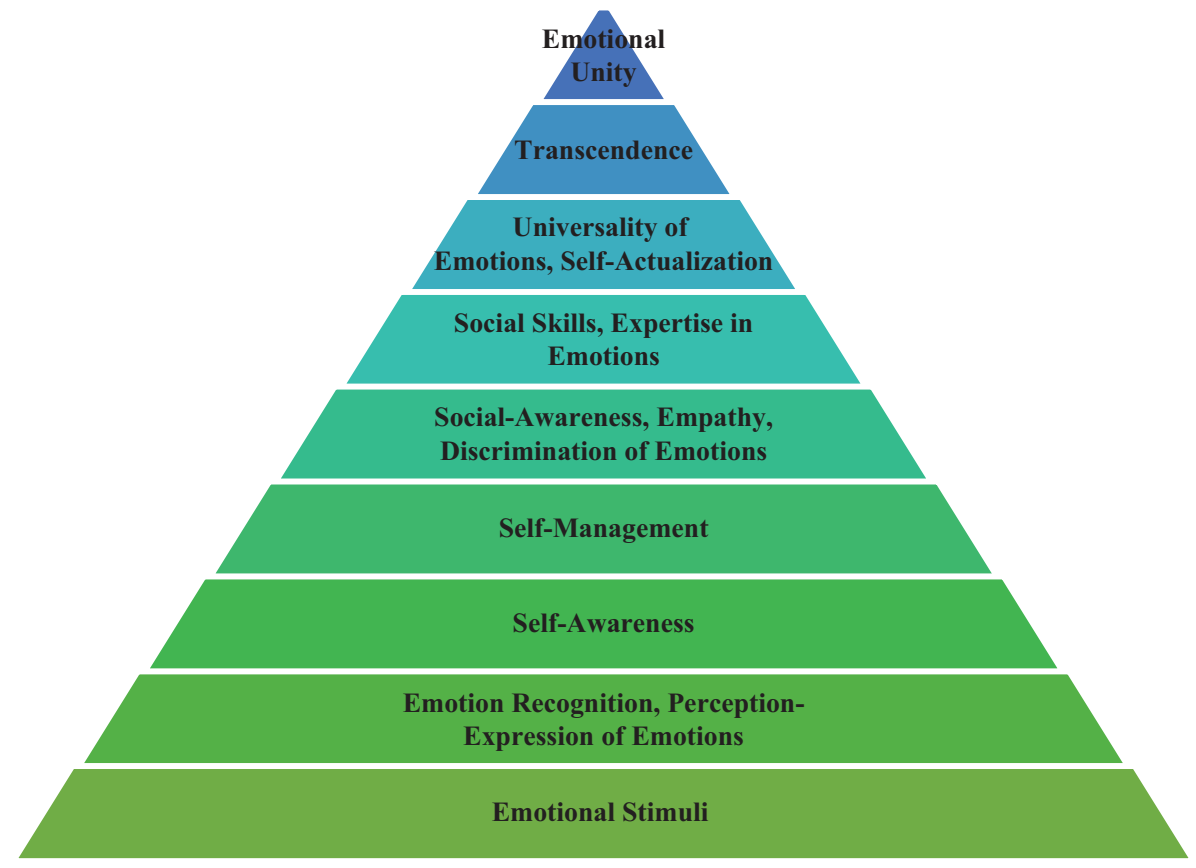

Fig. 1. The emotional intelligence pyramid (9-layer model) 
In this article we present the metacognitive and meta-emotional skills needed to develop the individual's emotional intelligence based on the pyramid model of emotional intelligence (Figure 1) [20]. Each level includes specific skills that the individual must focus on in order to cultivate and use them to evolve and level up towards self-improvement and self-knowledge. Many of these skills appear at other levels too, which shows their crucial role in the development and enhancement of emotional intelligence. In addition, in the article we present strategies that can be adopted for the cultivation of metacognitive and meta-emotional skills and will therefore contribute methodically to the promotion of emotional intelligence.

\section{The nine layers of the pyramid-Metacognitive and metaemotional skills: building the emotional intelligence}

The Layer of Emotional Stimuli - An emotional stimulus impacts behavior and physiology [21] and its appearance triggers an emotional reaction to the individual. Learning to use the metacognitive functions [22] of attention, memory and perception the person will detect and decode the emotional stimulus, and the emotional response may affect behavior and actions [23]. Selective and constant attention contributes to the rapid detection of emotional stimuli [24] and consequently to the processing and evaluation of each stimulus to discriminate among relevant and irrelevant ones for taking adaptive decisions and regulate flight, fight or freezing emotional responses. Furthermore, selective attention contributes to emotionally enhanced memory functions [22] that will help recall past emotional stimuli and connect with new ones. Emotional stimuli and emotional stimulation affect memory and enhance its formation and through cognitive and nervous mechanisms affect the amygdala and the memory areas of the inner temporal lobe that play an important role in its function [25]. Moreover, the observation of the sensory channels with alertness and vigilance to be in readiness for the input of the emotional stimulus to achieve one's goals is extremely important too. Stress or negative emotions can alter connectivity patterns between different areas of the brain, for example amygdala activations [26] either at rest or on emotional stimuli perception [27]. A careful bias toward positive emotional stimuli can be a protective factor in contributing to negative emotions resistance [28]. Appraisal of an emotional stimulus and an emotional response is always necessary and it is related to the perceiver's goals and expectations [29]. Interoception, at an early stage, is needed -Damasio names it "material me" -which is the perception and awareness of our body's internal state to start be aware of our inner feelings [30].

The Layer of Emotion Recognition - Perception and Expression of Emotions - Recognizing, perceiving and expressing emotions are important and vital elements for our personal, social and professional relationships. The evaluation of emotional stimuli in the previous layer and the increased attention and regulation to them contributes to the strengthening of the emotional memory and the retention of emotional information [31] for the brain to pass to higher emotional functions. Emotional memories will work more methodically in designing current behavior. Emotion-memory interactions occur at different stages of the processing of emotional information [25] and play a significant role in the recognition of emotions. Attention is needed to accurately 
decode, detect and recognize the emotional expressions of others, transmitted either verbal or non-verbal. Facial expressions can display personal emotions and indicate an individual's intentions within a social situation and, hence, are extremely important for social interaction [32]. Observation of the emotions leads to the interpretation and expression of them proportionally. Monitoring the pattern recognition and making associations contribute to the identification of the connection between emotions and situations and the response to them [33]. The recognition of emotions, helps focus on the emotional moment, deals with it effectively, promotes well-being in daily life [34] and develops stronger emotional health. The recognition and initial processing of emotions structures and enriches our emotional experiences, thus shaping our perceptions and awareness [35].

The Layer of Self-Awareness - Self-awareness is having a clear perception and realization of your personality, including your emotions, strengths, weaknesses, thoughts, beliefs, motives, values, needs (internal self-awareness) and ability to understand how other people view you (external self-awareness) [36]. Examining, reviewing and evaluating your emotions, your thoughts and your behavior helps you improve emotional granularity which enhances emotional intelligence. Self-awareness is a kind of mental perception [37]. Knowing yourself means understanding all the emotions that surround you, having the capacity for introspection, identifying how the emotions impact your thoughts, your actions, your performance and your behavior leading to self-improvement. Introspection for self-awareness is a process that requires time and patience to be effective and not lead to incorrect self-perceptions [36]. In addition, self-awareness extends to the knowledge of how our behavior, our actions affect those around us [38]. Self-monitoring your emotional state and your thoughts in a situation and assessing of your emotions, your strengths and weaknesses, will be the key for showing self-confidence, self-esteem and will increase your self-awareness. Self-monitoring is a very important ability in understanding, controlling and evaluating our emotional state resulting in objective self-knowledge and possible improvements in our behavior and actions to address an issue [39]. Self-focused attention in the third layer is also needful and can lead to conscious awareness and self-evaluation, automatic or conscious one [40]. Attention and clarity are important abilities for emotional self-awareness [41]. Self-reflection, the ability to look deep into and evaluate our own emotional, cognitive and behavioral processes, leads to increased self-awareness [42]. With self-awareness one can manage himself/herself both preventively and in action.

The Layer of Self-Management - Self-management is the ability to use your self-awareness to control your emotions, your impulses, your reactions, your responses and simultaneously, take the responsibility of them and manage the condition. The ability of emotion regulation is a process of managing emotions, positive and negative ones, and can be automatic or controlled, conscious or unconscious [43,44]. It is about maintaining desirable emotional states and stopping or handling unwanted ones [45]. Reappraisal is a cognitive change about a situation that elicitates emotions [43] and involves reviewing an emotional situation taking into account different perspectives [46]. Cognitive reappraisal skills may include practices such as thought replacement or situational role reversals, where we try to look into an emotional situation from a whole new perspective. Reframing is an ability that consists of identifying and changing the way situations, experiences, events, ideas, emotions, learning are dealt with [47]. 
Attention to emotions and emotional reactions and regulation of attention is also necessary in the regulatory process of emotions, which in combination with reappraisal can help to achieve the level of self-management [45]. Self-assessment of regulatory behavior in a situation and comparison with previous ones leads to better self-management and better coping with emotionally charged situations [48]. Emotional flexibility is also a necessary skill. It is related to the ability to adapt to changing emotional contexts [49], to deal better with an emotional situation and regulate emotions accordingly [50] and pursue our values and goals.

The Layer of Social Awareness, Empathy and Discrimination of Emotions - The cultivation of the previous layer is the basis for the individual to move on from the emotional self to the emotional selves of others. The skills of attention and observation of facial - verbal expressions and of body language of others to understand their thoughts and feelings and how your emotional reactions impact them are extremely necessary [51]. Flexibility and adaptability are important skills for that layer to understand other people and to respond effectively and see things from their perspective. Social cognition, also useful, is the cognitive ability that helps us perceive other people's thoughts, feelings, and intentions to understand and predict their behavior and to interpret the social and emotional messages that come from one's surroundings [52]. Emotional monitoring and sensitivity to social-emotional cues of others help individuals understand others' emotions and control their interactions [53]. Empathic listening skills (sensing, processing, and responding), also called active or reflective, are required for better communication to respond appropriately to others' emotions and feelings [54]. Metacognitive awareness ability is indispensable to be aware of your emotions and thoughts and about your ability to understand the emotions and the thoughts of others [55]. The skill of discrimination between emotions (relevant, valid, important) promotes the willingness to transform difficult situations and tendencies into constructive thoughts, feelings, and actions.

The Layer of Social Skills, Expertise in Emotions - Social skills are a set of behaviors that are needed to interact and relate to others effectively and satisfactorily [56]. At this level the emotionally intelligent person can inspire, collaborate, interact constructively and influence others positively helping them with the management of their emotions too. Attention during interactions and social-management to control impulses to navigate social communications are prerequisites for successful implied social skills. Cognitive flexibility is also needed at this level to see the world from different angles, to be flexible enough to change the minds or the emotions of others in a positive way and manage an emotionally charged situation in which other people are involved [7]. Emotional granularity is needed to distinguish between the specificity of emotions, to be precise between emotions of similar valance based on emotional experiences [57] in order to have expertise in emotions. Expertise in the field of emotions is characterized by extensive and specific emotional knowledge based on emotional experience and by skills in processing emotional information [58] and understand of what other people are experiencing. Experts in emotions delve into memory, easily adapt to situations with cognitive or emotional content through the process of self-regulation and comprehend their own and others mental and emotional states. Mental representation of emotional experience is an important and necessary skill in expertise for gathering emotional information from ourselves and from the world [59]. Problem solving skills 
is part of the thought process and important in social skills. It is considered a complex mental function and has been defined as a high level cognitive and behavioral process for finding solutions to problems encountered in life and dealing with them [60]. Social reasoning is also useful to draw conclusions about the intentions, moods, emotions and actions of others in order to regulate one's behavior [61].

The Layer of Self-Actualization - Self-actualization is the realization and development of one's full, unique potentials which include talents, capabilities etc. [62]. It is a process of continual ongoing personal growth. Emotional intelligence and self-actualization are strongly correlated [63]. Self-concept, self-perception and self-efficacy are must-have skills and are the beliefs we have about ourselves (behavior, abilities) to develop our personality and to achieve our goals [61]. Self-compassion is an ability associated with a more general improvement in the way we think and understand ourselves, but also in how we feel about ourselves as a whole, which brings about a significant change in how we handle difficult situations in our lives [64]. It may actually increase self-improvement motivation. Self-realization is also essential to understand and evaluate your real self [65], and living more fully. Creativity and flexibility are needed skills for motivation for self-actualization [66]. Planning, monitoring, evaluating, and regulating oneself are metacognitive abilities for the fulfillment of one's potentials [67]. Emotional agility is the ability to manage one's emotions and thoughts with mindful and productive way to give the best self [7]. Savoring is another skill required for self-actualization that encloses conscious awareness and deliberate attention to pleasant experiences [68]. It is also defined as a beneficial interpretation of positive events.

The Layer of Transcendence - One shows genuine concern for others and helps them to find self-fulfillment, realize their potential and self-actualize [69]. It is the expansion of boundaries of self-concept and self-limitations [70] and gaining new perspectives. An emotionally intelligent individual not only possesses the skills for self-motivation and self-perfection but also the skills required to motivate others. Self-transcendence is the experience of seeking ultimate meaning to yourself, to others and to the world. Emotional resilience is a skill and an art of living that is entwined with self-belief, self-compassion, global empathy and enhanced cognition to find the true meaning of one's own life [71]. It is intrinsic motivation [71], an inner force by which we can hold ourselves through all the downsides of life. In the layer of transcendence dominate strong positive emotions like joy, peace, and a well-developed sense of awareness. The skill of interpretation of experiences and current reality is needful [72]. Introspection, attention and memory to clarify and expand knowledge about self and find or create meaning and purpose in the experience [73]. Self-reflection plays a key role in transcendence and it is the ability to observe, meditate on and evaluate your own cognitive, emotional and behavioral processes and includes the personal will to learn more about your goals, essence and true self [61]. Monitoring self, others and universe as a third-person perspective to recognize their potential and go beyond oneself.

The Layer of Emotional Unity - The highest level in the pyramid of emotional intelligence, refers to an internal harmony [74] where joy, euphoria, peace, and unity of all things dominate. In emotional unity what you do for yourself, you ultimately do for the other person and for everything that exists around us through a sense of collective responsibility and common fate [75]. Empathy, appreciation, and protection for the 
welfare of all people and for nature prevail [76] and actions that harm others or the planet [77] are avoided due to the feeling of connectedness being part of a larger whole to create harmony in life. In emotional unity difficult stressful times encourage people to reassess their emotions, their priorities, their goals and thinking that they belong to a community working for the common good. Consciousness is experienced as a vast spectrum of awareness, ranging from completely unconscious to fully awakened. Self-consciousness skill is an increased sense of self-awareness. It is a concern with oneself and its interactions with the environment - including others [78]. Flexibility is needed to face adaptively the continuous changes within the person, with others and with different contexts, including the natural world [74]. Self-attunement, a vital skill, which is a full and deep access to the mind, heart and body to achieve greater self and social awareness [79,74]. Last, the skills of attention, self-observation and self-evaluation are functional so as to accurately assess the world and interpretate emotional reality [80].

It is worth noting that the metacognitive skills of self-regulation, self-monitoring, attention, memory, flexibility go through all the stages of the pyramid levels, from the level at the base They are skills that traverse all levels and the transition from one layer to another requires ever higher capacities from the same skill each time. The degree of use of abilities differs when one process a simple emotional response, a more complex emotional situation or an emotional charged situation involving oneself and other people too. For example, emotional self-regulation is the ability to respond to the ongoing demands of the emotional experience with the range of emotions in a way that is socially tolerable and flexible enough to allow spontaneous reactions, as well as the ability to delay spontaneous ones [81]. The regulation of emotion concerns and includes, the shaping of the emotions that a person experiences, when he/she experiences them but also the ways in which he/she expresses them. Specifically, at the level of emotional stimuli we regulate quick emotional reactions/responses affected by the stimuli but at the level of transcendence and emotional unity the regulatory mechanisms are such that we can respond to more complex situations for emotional self and others, to distinguish between subjective and objective observations to assess accurately the world. Emotional regulation entails processes involved in monitoring, evaluating, and modifying our emotional experiences [82]. Self-monitoring is a conscious attention and observation [83], a state of concentration and assessment procedure in what is happening inside us as far emotions, thoughts and behaviors are concerned. The individual adopts a third person perspective with access to memory and first becomes an observer of emotional stimuli and responses, then of himself and others to the observer of the universe. Attention helps in the quick and easy acquisition of emotional information but also in the proper processing and interpretation of it and memory refers to the knowledge of our own memory possibilities, to our limitations, to our ability to relate previously stored emotional knowledge to new ones, to the way in which we usually retrieve and utilize emotional information [84]. Adaptability is an individual's ability (due to inclination, motivation and willpower) to adapt or change to cope with a new different situation, a change in the environment [84]. It is inextricably linked with memory and inhibitory control [84] and presupposes good contact with ourselves, awareness of our feelings and needs. 


\section{The nine layers of the pyramid-Additional strategies for the development and strengthening of emotional intelligence}

The Layer of Emotional Stimuli - Detect the stimuli (external or internal one) and try to locate their origin to be aware of next time. Observe what emotional responses each stimulus causes to regulate fight-or-flight reactions for self-preservation. Observe how your body reacts to different emotional triggers. Once you increase personal awareness of your own specific set of emotional triggers, you can begin the process of learning how to recognize and regulate your emotions [85]. Sensory stimulation interventions, body-mind and attention training will activate the senses for the recognition and interpretation of emotional stimuli $[86,87]$. Mnemonic strategies are used by people to organize and give importance to the material they want to memorize. Repetitive activity leads to long-term changes in synaptic compounds and appear as a background of long-term memory [88].

The Layer of Emotion Recognition - Perception and Expression of Emotions Try to recognize the emotions of others and yours by paying attention and be present. Broaden your emotional vocabulary to recognize and label the exact emotion each time. All kind of emotions, positive or negative ones, are important. Accept, evaluate and express your emotions calmly and in an accurate way. Emotional suppression and inhibition have negative consequences on mental and physical health [89,90].

The Layer of Self-Awareness - Monitor and observe your emotions, and name them, positive or negative ones. Be honest with yourself about what you are really feeling. Note down your feelings and the cause of them to be more aware of yourself. Accept your emotions and yourself as a personality with the strengthens and weaknesses. Be open to get feedback from others to see yourself from another's perspective. There are applications, games and devices that promote the user's self-knowledge and self-awareness of the gathered emotional data [83]. View yourself objectively. Motivate to be better. Pay attention to your emotions, especially the intense ones, in order to understand the reason for their creation. Thus, we increase our self-awareness and the effect that behavior has on those around us.

The Layer of Self-Management - Exercise and choose positive activities to release good hormones like serotonin, norepinephrine and dopamine that play a key role in modulating and regulating behavior and anxiety [91]. Quit negative habits that take you away from self-management and emotional intelligence [92]. Be open, emotionally present, appreciate and accept what is going on around you. Positive way of thinking. Avoid excessive criticism of others or of situations. Take deep breaths [93], be calm, try to manage stress or negative emotions before they overwhelm you and regulate your emotional responses and actions. Distinguish emotions from reason. Always think about how you handled a situation and consider the consequences of your actions. Some emotion regulation strategies are situation modification, attentional deployment, cognitive change, and response modulation [44,93].

The Layer of Social Awareness, Empathy and Discrimination of Emotions Listen with empathy [94] without judging, put yourself in the other person's shoes and try to look from their perspective [51]. Attention to the emotions of others expressed either verbal or the non-verbal better social-awareness. Interaction with people. 
Live in the moment [51]. Adaptive coping strategies include active coping, planning, positive reframing, acceptance, humor, religion, and using emotional and instrumental support [95].

The Layer of Social Skills, Expertise in Emotions - Communicate and cooperate with others. Constructive interactions. Communicate your thoughts and emotions [59]. Encourage people to take part in conversation. Listen to what others say and pay attention to their talking and the experiences of emotion of others. Laughter brings your nervous system into balance, reducing stress, calming you down, sharpening your mind and making you more empathic. Be receptive to feedback from social others [96]. Handle emotional situations by regulating your emotions and the emotions of others for better problem-solving.

The Layer of Self-actualization - To become a fully functioning person be open to experiences and try to learn new things [97]. Engage yourself in activities that give a sense of contribution, acceptance, and self-valuing [97]. Step out of your comfort zone. Accept yourself and be present with all your senses. Learn from mistakes and have self-confidence. Setting a goal for yourself (short-term and/or long term), try to do your best and check your progress. Positive and realistic attitude towards life and step back from negative thoughts which work as cognitive distortions. Reflective technology to assist in developing user's self-actualization [66]. Cultivate positive emotions to promote resilience [98]. Appreciation and enhancement of positive experiences, emotions and aspects of life. Awareness of what things improve or worsen your mood and behavior. Have self-respect, and respect others too.

The Layer of Transcendence - Become selfless or egoless and oriented to caring for and helping others $[99,100]$. Do some activities that promote altruism and creativity. Rising moral concerns [101]. Practice excellence in everything you do. Adjusting well to your present life situation and have positive thinking. Sharing your wisdom or experience [73]. Pray [102], and choose any activity that helps in the search for connectedness within self and with others [103]. Be openness to change [104] and accept responsibility. Visualization, life review, structured reminiscence, and journaling [73] are strategies for develop the layer of transcendence.

The layer of Emotional Unity - Go into nature [105] and feel the close relationship. Be always present and increase your full awareness of your internal and external experiences. Find out your true values in life. Learn how to consciously connect with your body. Be a lifelong learner. Create conscious and strong relationships. Monitor and try to understand the true meaning behind your social interactions and personal actions. Caring (for yourself, for others, for planet) and feel the unity of the emotions [74].

A strategy that is very useful in all stages of the pyramid from the first related to emotional stimuli to the last with emotional unity and benefits attention, emotional balance, emotional state and change, mental resilience, self-efficacy and perceived stress is mindfulness. There is a positive relationship between mindfulness and emotional intelligence with mindfulness contributing to its development and enhancement [106]. Mindfulness is observing thoughts, feelings, and senses in the present moment without judging them as good or bad $[107,108]$. It emerges through observation, awareness and cultivation of positive emotions. This practice leads the person to cultivate consciousness [109], which helps to calm the inner self and improve the person's relationships. Furthermore, the person learns more easily to accept his/her thoughts and emotions. 
Meditation is a form of mindfulness and spiritual concentration that is achieved by deep relaxation, the removal of any thought and external stimuli from the subject's consciousness to improve an individual's psychological and emotional capacities, such as attentional and emotional self-regulation [110]. Meditation is a practice for developing and cultivating consciousness.

Sleep, nutritional factors, physical exercise, computer training, brain stimulation help cognitive and emotional capacities to operate more effectively and develop emotional intelligence $[88,111]$.

\section{Discussion and conclusion}

Emotions are one of the core components that characterize human beings, with physiological, affective, behavioral, and cognitive elements [83]. Emotional intelligence describes a set of abilities and skills to recognize, evaluate and manage the emotions of oneself and of others. It facilitates our capacity for resilience, motivation, empathy, reasoning, problem - solving, stress management, social interaction, and resolution of conflicts [112]. The scope of the current study was to map the skills involved in each layer of the pyramid of emotional intelligence [20]. These abilities and skills must be trained and be developed gradually and hierarchically to reach emotional self-realization [6].

The cultivation and training of these metacognitive and metaemotional abilities and skills with strategies is essential for the increase of EI and has a huge impact on our personality and on all kinds of relationships that an individual might have. All levels of the pyramid (Figure 1), from responding to emotional stimuli to feeling emotionally united, each have their own metacognitive and metaemotional skills whose progressive mastery contributes to their development. Each layer represents a higher state of emotional intelligence, self-knowledge, self-actualization and consciousness. The determining role for the evolvement of these skills is played by the effort an individual exerts. Repeated practice will lead the strategy to be automated [113] and consequently the metacognitive and metaemotional skills become automatic too, requiring minimal effort each time [98]. It is worth noting that some metacognitive functions such as attention, memory, regulation, awareness, monitoring, observation are encountered at all levels.

Acquiring these skills will not only increase emotional intelligence but also improve physical, intellectual and spiritual intelligence and individuals will be more attentive and conscious, motivated, less stressful, self-controlled and resilient [114] having an improving mindset. Emotionally intelligent people are interested in overall success and achieving goals for not only themselves but for other people too because they perceive their own self as a part of a social whole.

The metacognitive and metaemotional skills mentioned in the article in the layered pyramid model of emotional intelligence such as attention, self-regulation, awareness, flexibility, monitoring, evaluation can be trained and applied in a variety of contexts such as the educational framework, the work framework for a holistic emotional learning and thus contributing in developing emotional intelligence and self-improvement and in accelerating the success of students, employees, leaders and citizens in general in many aspects of their lives. Curricula integrated these skills would be very important and promising to promote critical social and emotional competencies for all students 
[115]. The development and enhancement of emotional intelligence through the learning and training of strategies and skills will act as a catalyst in the work environment resulting in better performance and well-being on the part of employees and leaders [116]. The creation of technological tools that help the user in learning and enhancing these skills will also contribute to this direction. People as units or participating in a special seminar could try to practice and use the aforementioned strategies and skills to gradually and patiently conquer all the important stages of the pyramid of emotional intelligence, to obtain self-awareness, better regulation of themselves and their emotions, to show empathy, to have social awareness for maintaining harmonious relationships with others and to live in better harmony with the environment and the society. The intelligent use and coordination of emotions and behavior is a fundamental mechanism for psychological adaptation and well-being.

In order to achieve our maximum potential in our professions, relationships, and as purposeful human beings, it is imperative that we discern and develop our EI. It enhances our working abilities, improves our social interactions, contributes to the proper functioning of the cognitive, emotional and psychophysiological mechanism of the individual but it also supports satisfaction, contentment, emotional well-being and the ability to better enjoy many aspects of everyday life.

It is extremely important to create metacognitive and metaemotional learning environments based on systematic training of skills and strategies to proceed from emotional stimuli to emotion recognition and expression, from emotional recognition and perception to self-awareness, to self-management until we reach self-actualization, transcendence and emotional unity to achieve virtue, happiness, and meaning.

The metacognitive and metaemotional capacity of individuals is not constant, but it is in a continuous process of development and evolution [117]. The development of cognition and emotion has an evolutionary progression at different ages of children, which goes hand in hand with the development of the cognitive system, while the growth rate can be increased with didactic intervention. Thoughts, emotions and physical condition prove to be a single whole, composed of concentric worlds that interact with each other, while the same events produce results at completely different times and at completely different speeds.

Through this study, we presented the metacognitive and metaemotional skills and strategies that are required to develop and cultivate our emotional intelligence and are interconnected in a dynamic set, increasing the projection of the true self of knowledge into an emotionally unified universe [118]. Ascending from lower to higher layers of the pyramid implies moving to advanced forms of metacognitive and metaemotional skills and because there is interconnection between the layers any improvement or dysfunction affects positively or negatively the human condition. By learning that skills and strategies, human beings can develop and boost their emotional intelligence.

\section{$5 \quad$ References}

[1] Bao, X., Xue, S., \& Kong, F. (2015). Dispositional mindfulness and perceived stress: The role of emotional intelligence. Personality and Individual Differences, 78, 48-52. https://doi.org/10.1016/j.paid.2015.01.007 
[2] Di Fabio, A., \& Kenny, M. E. (2016). Promoting well-being: The contribution of emotional intelligence. Frontiers in Psychology, 7, 1182. https://doi.org/10.3389/fpsyg.2016.01182

[3] Goleman, D. (2021). Leadership: The power of emotional intelligence. More Than Sound LLC.

[4] Miao, C., Humphrey, R. H., \& Qian, S. (2017). A meta-analysis of emotional intelligence and work attitudes. Journal of Occupational and Organizational Psychology, 90(2), 177-202. https://doi.org/10.1111/joop.12167

[5] Puertas Molero, P., Zurita Ortega, F., Chacón-Cuberos, R., Castro Sánchez, M., Ramírez Granizo, I. A., \& González Valero, G. (2020). Emotional intelligence in the field of education: a meta-analysis. Anales de Psicología, 36, 84-91. 10.6018/analesps.36.1.345901

[6] Drigas, A., \& Papoutsi, C. (2021). Nine layer pyramid model questionnaire for emotional intelligence. International Journal of Online \& Biomedical Engineering, 17(7). https://doi. org/10.3991/ijoe.v17i07.22765

[7] Eichbaum, Q. G. (2014). Thinking about thinking and emotion: The metacognitive approach to the medical humanities that integrates the humanities with the basic and clinical sciences. The Permanente Journal, 18(4), 64. https://doi.org/10.7812/TPP/14-027

[8] Caro Pineres, M. F., \& Jimenez Builes, J. A. (2013). Analysis of models and metacognitive architectures in intelligent systems. Dyna, 80(180), 50-59.

[9] Quirk M. Intuition and metacognition in medical education: Keys to developing expertise. New York, NY: Springer Publishing Company, Inc; 2006.

[10] Briñol, P., Petty, R. E., \& Rucker, D. D. (2006). The role of meta-cognitive processes in emotional intelligence. Psicothema, 18(Suppl), 26-33.

[11] Wheaton, A. (2012). Metacognition and emotional intelligence. Australian Educational Leader, 34(1), 38-41.

[12] Becker-Asano, C., \& Wachsmuth, I. (2008, September). Affect simulation with primary and secondary emotions. In International Workshop on Intelligent Virtual Agents (pp. 15-28). Springer, Berlin, Heidelberg. https://doi.org/10.1007/978-3-540-85483-8 2

[13] Kelly, K. J., \& Metcalfe, J. (2011). Metacognition of emotional face recognition. Emotion, 11(4), 896. https://doi.org/10.1037/a0023746

[14] Srinivasan, D. P., \& Pushpam, M. M. (2016). Exploring the influence of metacognition and metaemotion strategies on the outcome of students of IX Std. American Journal of Educational Research, 4(9), 663-668.

[15] Mitmansgruber, H., Beck, T. N., Höfer, S., \& Schüßler, G. (2009). When you don't like what you feel: Experiential avoidance, mindfulness and meta-emotion in emotion regulation. Personality and Individual Differences, 46(4), 448-453. https://doi.org/10.1016/j. paid.2008.11.013

[16] Drigas, A., \& Mitsea, E. (2020). The 8 pillars of metacognition. International Journal of Emerging Technologies in Learning (iJET), 15(21), 162-178. https://doi.org/10.3991/ijet. v15i21.14907

[17] Hodzic, S., Scharfen, J., Ripoll, P., Holling, H., \& Zenasni, F. (2018). How efficient are emotional intelligence trainings: A meta-analysis. Emotion Review, 10(2), 138-148. https:// doi.org/10.1177/1754073917708613

[18] Mattingly, V., \& Kraiger, K. (2019). Can emotional intelligence be trained? A metaanalytical investigation. Human Resource Management Review, 29(2), 140-155. https://doi. org/10.1016/j.hrmr.2018.03.002

[19] Davidson, R. J., Jackson, D. C., \& Kalin, N. H. (2000). Emotion, plasticity, context, and regulation: Perspectives from affective neuroscience. Psychological Bulletin, 126(6), 890. https://doi.org/10.1037/0033-2909.126.6.890

[20] Drigas, A. S., \& Papoutsi, C. (2018). A new layered model on emotional intelligence. Behavioral Sciences, 8(5), 45. https://doi.org/10.3390/bs8050045 
[21] Bornemann, B., Winkielman, P., \& Van der Meer, E. (2012). Can you feel what you do not see? Using internal feedback to detect briefly presented emotional stimuli. International Journal of Psychophysiology, 85(1), 116-124. https://doi.org/10.1016/j.ijpsycho.2011.04.007

[22] Vuilleumier, P. (2005). How brains beware: Neural mechanisms of emotional attention. Trends in Cognitive Sciences, 9(12), 585-594. https://doi.org/10.1016/j.tics.2005.10.011

[23] Matthews, G., Zeidner, M., \& Roberts, R. D. (2017). Emotional intelligence, health, and stress. The handbook of stress and health: A guide to research and practice, 312-326. https://doi.org/10.1002/9781118993811.ch18

[24] Chun, M. M., Golomb, J. D., \& Turk-Browne, N. B. (2011). A taxonomy of external and internal attention. Annual Review of Psychology, 62, 73-101. https://doi.org/10.1146/ annurev.psych.093008.100427

[25] LaBar, K. S., \& Cabeza, R. (2006). Cognitive neuroscience of emotional memory. Nature Reviews Neuroscience, 7(1), 54-64. https://doi.org/10.1038/nrn1825

[26] Shin, L. M., \& Liberzon, I. (2010). The neurocircuitry of fear, stress, and anxiety disorders. Neuropsychopharmacology, 35(1), 169-191. https://doi.org/10.1038/npp.2009.83

[27] Khosrowabadi, R. (2018). Stress and perception of emotional stimuli: Long-term stress rewiring the brain. Basic and Clinical Neuroscience, 9(2), 107. https://doi.org/10.29252/ nirp.ben.9.2.107

[28] Thoern, H. A., Grueschow, M., Ehlert, U., Ruff, C. C., \& Kleim, B. (2016). Attentional bias towards positive emotion predicts stress resilience. PloS One, 11(3), e0148368. https://doi. org/10.1371/journal.pone. 0148368

[29] Olteanu, L., Golani, S., Eitam, B., \& Kron, A. (2019). The effect of relevance appraisal on the emotional response. Emotion, 19(4), 715. https://doi.org/10.1037/emo0000473

[30] Craig, A. D. (2003). Interoception: The sense of the physiological condition of the body. Current Opinion in Neurobiology, 13(4), 500-505. https://doi.org/10.1016/S0959-4388(03) 00090-4

[31] Brosch, T., Scherer, K. R., Grandjean, D. M., \& Sander, D. (2013). The impact of emotion on perception, attention, memory, and decision-making. Swiss Medical Weekly, 143, w13786. https://doi.org/10.4414/smw.2013.13786

[32] Xu, Q., Yang, Y., Tan, Q., \& Zhang, L. (2017). Facial expressions in context: Electrophysiological correlates of the emotional congruency of facial expressions and background scenes. Frontiers in Psychology, 8, 2175. https://doi.org/10.3389/fpsyg.2017.02175

[33] Guarnera, M., Hichy, Z., Cascio, M. I., \& Carrubba, S. (2015). Facial expressions and ability to recognize emotions from eyes or mouth in children. Europe's Journal of Psychology, 11(2), 183. https://doi.org/10.5964/ejop.v11i2.890

[34] Stanton, A. L., \& Low, C. A. (2012). Expressing emotions in stressful contexts: Benefits, moderators, and mechanisms. Current Directions in Psychological Science, 21(2), 124-128. https://doi.org/10.1177/0963721411434978

[35] Brosch, T., Pourtois, G., \& Sander, D. (2010). The perception and categorisation of emotional stimuli: A review. Cognition and Emotion, 24(3), 377-400. https://doi.org/10.1080/ $\underline{02699930902975754}$

[36] Eurich, T. (2018). What self-awareness really is (and how to cultivate it). Harvard Business Review.

[37] Kobayashi, H. (2010). Self-awareness and mental perception. Journal of Indian Philosophy, 38(3), 233-245. https://doi.org/10.1007/s10781-010-9096-6

[38] Axelrod, S. D. (2012). "Self-awareness": At the interface of executive development and psychoanalytic therapy. Psychoanalytic Inquiry, 32(4), 340-357. https://doi.org/10.1080/07 351690.2011 .609364 
[39] Riemer, V., \& Schrader, C. (2019). Mental model development in multimedia learning: Interrelated effects of emotions and self-monitoring. Frontiers in Psychology, 10, 899. https://doi.org/10.3389/fpsyg.2019.01174; https://doi.org/10.3389/fpsyg.2019.00899

[40] Silvia, P. J., \& Phillips, A. G. (2013). Self-awareness without awareness? Implicit selffocused attention and behavioral self-regulation. Self and Identity, 12(2), 114-127. https:// doi.org/10.1080/15298868.2011.639550

[41] Boden, M. T., \& Thompson, R. J. (2017). Meta-analysis of the association between emotional clarity and attention to emotions. Emotion Review, 9(1), 79-85. https://doi. org/10.1177/1754073915610640

[42] Johnson, S. C., Baxter, L. C., Wilder, L. S., Pipe, J. G., Heiserman, J. E., \& Prigatano, G. P. (2002). Neural correlates of self-reflection. Brain, 125(8), 1808-1814. https://doi.org/ 10.1093/brain/awf181

[43] Gross, J. J. (1998). The emerging field of emotion regulation: An integrative review. Review of General Psychology, 2(3), 271-299. https://doi.org/10.1037/1089-2680.2.3.271

[44] Peña-Sarrionandia, A., Mikolajczak, M., \& Gross, J. J. (2015). Integrating emotion regulation and emotional intelligence traditions: A meta-analysis. Frontiers in Psychology, 6, 160. https://doi.org/10.3389/fpsyg.2015.00160

[45] Wadlinger, H. A., \& Isaacowitz, D. M. (2011). Fixing our focus: Training attention to regulate emotion. Personality and Social Psychology Review, 15(1), 75-102. https://doi. org/10.1177/1088868310365565

[46] Aldao, A., Nolen-Hoeksema, S., \& Schweizer, S. (2010). Emotion-regulation strategies across psychopathology: A meta-analytic review. Clinical Psychology Review, 30(2), 217-237. https://doi.org/10.1016/j.cpr.2009.11.004

[47] Barker, C., Martin, B., \& Zournazi, M. (2008). Emotional self-management for activists. Reflective Practice, 9(4), 423-435. https://doi.org/10.1080/14623940802431457

[48] Mooney, P., Ryan, J. B., Uhing, B. M., Reid, R., \& Epstein, M. H. (2005). A review of self-management interventions targeting academic outcomes for students with emotional and behavioral disorders. Journal of Behavioral Education, 14(3), 203-221. https://doi.org/ $10.1007 / \mathrm{s} 10864-005-6298-1$

[49] Beshai, S., Prentice, J. L., \& Huang, V. (2018). Building blocks of emotional flexibility: Trait mindfulness and self-compassion are associated with positive and negative mood shifts. Mindfulness, 9(3), 939-948. https://doi.org/10.1007/s12671-017-0833-8

[50] Fu, F., Chow, A., Li, J., \& Cong, Z. (2018). Emotional flexibility: Development and application of a scale in adolescent earthquake survivors. Psychological Trauma: Theory, Research, Practice, and Policy, 10(2), 246. https://doi.org/10.1037/tra0000278

[51] Bradberry, T., \& Greaves, J. (2009). Emotional Intelligence 2.0. TalentSmart.

[52] Benito, A., Lahera, G., Herrera, S., Muncharaz, R., Benito, G., Fernández-Liria, A., \& Montes, J. M. (2013). Deficits in recognition, identification, and discrimination of facial emotions in patients with bipolar disorder. Brazilian Journal of Psychiatry, 35(4), 435-438. https://doi.org/10.1590/1516-4446-2013-1086

[53] Grieve, R. (2011). Mirror mirror: The role of self-monitoring and sincerity in emotional manipulation. Personality and Individual Differences, 51(8), 981-985. https://doi.org/ 10.1016/j.paid.2011.08.004

[54] Shrivastava, A. (2014). Active empathic listening as a tool for better communication. International Journal of Marketing \& Business Communication, 3(3/4), 13-18.

[55] Kallio, H., Virta, K., \& Kallio, M. (2018). Modelling the components of metacognitive awareness. International Journal of Educational Psychology, 7(2), 94-122. https://doi. org/10.17583/ijep.2018.2789 
[56] Salavera, C., Usan, P., \& Jarie, L. (2017). Emotional intelligence and social skills on self-efficacy in secondary education students. Are there gender differences? Journal of Adolescence, 60, 39-46. https://doi.org/10.1016/j.adolescence.2017.07.009

[57] Lee, J. Y., Lindquist, K. A., \& Nam, C. S. (2017). Emotional granularity effects on eventrelated brain potentials during affective picture processing. Frontiers in Human Neuroscience, 11, 133. https://doi.org/10.3389/fnhum.2017.00133

[58] McBrien, A., Wild, M., \& Bachorowski, J. A. (2020). Social-emotional expertise (SEE) scale: Development and initial validation. Assessment, 27(8), 1718-1730. https://doi. org/10.1177/1073191118794866

[59] Hoemann, K., Nielson, C., Yuen, A., Gurera, J., Quigley, K., \& Barrett, L. F. (2020). Expertise as a unifying framework for individual differences in the mental representation of emotional experience. https://doi.org/10.31234/osf.io/grkcm

[60] Dereli-Iman, E. (2014). The effect of the values education programme on 5.5-6 year old children's social development: Social skills, psycho-social development and social problem solving skills. Educational Sciences: Theory and Practice, 14(1), 262-268. https://doi. org/10.12738/estp.2014.1.1679

[61] Levesque, R. J. (Ed.). (2011). Encyclopedia of adolescence. Springer Science \& Business Media. https://doi.org/10.1007/978-1-4419-1695-2

[62] Krems, J. A., Kenrick, D. T., \& Neel, R. (2017). Individual perceptions of self-actualization: What functional motives are linked to fulfilling one's full potential? Personality and Social Psychology Bulletin, 43(9), 1337-1352. https://doi.org/10.1177/0146167217713191

[63] Bar-On, R. (2001). Emotional intelligence and self-actualization. In J. Ciarrochi, J. P. Forgas, \& J. D. Mayer (Eds.), Emotional intelligence in everyday life: A scientific inquiry (pp. 82-97). Psychology Press.

[64] Neff, K. D. (2003). The development and validation of a scale to measure self-compassion. Self and Identity, 2(3), 223-250. https://doi.org/10.1080/15298860309027

[65] Das, A. K. (1989). Beyond self-actualization. International Journal for the Advancement of Counselling, 12(1), 13-27. https://doi.org/10.1007/BF00123452

[66] Burleson, W. (2005). Developing creativity, motivation, and self-actualization with learning systems. International Journal of Human-Computer Studies, 63(4-5), 436-451. https://doi. org/10.1016/j.ijhcs.2005.04.007

[67] Dezhbankhan, F., Baranovich, D. L., \& Abedalaziz, N. (2020). Impacts of direct metacognitive instructions on self-actualization. International Education Studies, 13(11), 1-9. https:// doi.org/10.5539/ies.v13n11p1

[68] Tugade, M. M., \& Fredrickson, B. L. (2007). Regulation of positive emotions: Emotion regulation strategies that promote resilience. Journal of Happiness Studies, 8(3), 311-333. https://doi.org/10.1007/s10902-006-9015-4

[69] Huitt, W. (2001). Motivation to learn: An overview. Educational Psychology Interactive, 12.

[70] Coward, D. D., \& Reed, P. G. (1996). Self-transcendence: A resource for healing at the end of life. Issues in Mental Health Nursing, 17(3), 275-288. https://doi.org/10.3109/ 01612849609049920

[71] Wong, P. T. (2016). Meaning-seeking, self-transcendence, and well-being. In Logotherapy and existential analysis (pp. 311-321). Springer, Cham. https://doi. org/10.1007/978-3-319-29424-7 27

[72] Lawong, D., McAllister, C., Ferris, G. R., \& Hochwarter, W. (2018). Mitigating influence of transcendence on politics perceptions' negative effects. Journal of Managerial Psychology. https://doi.org/10.1108/JMP-09-2017-0337

[73] Reed, P. G. (2008). Theory of self-transcendence. Middle Range Theory for Nursing, 3, $105-129$. 
[74] Di Fabio, A., \& Tsuda, A. (2018). The psychology of harmony and harmonization: Advancing the perspectives for the psychology of sustainability and sustainable development. Sustainability, 10(12), 4726. https://doi.org/10.3390/su10124726

[75] Rai, T. S., \& Fiske, A. P. (2011). Moral psychology is relationship regulation: Moral motives for unity, hierarchy, equality, and proportionality. Psychological Review, 118(1), 57. https:// doi.org/10.1037/a0021867

[76] Schwartz, S. H. (2012). An overview of the Schwartz theory of basic values. Online Readings in Psychology and Culture, 2(1), 2307-0919. https://doi.org/10.9707/2307-0919.1116

[77] Bateson, G. Mind and Nature: A Necessary Unity; Dutton: New York, NY, USA, 1979; p. 238.

[78] Keromnes, G., Chokron, S., Celume, M. P., Berthoz, A., Botbol, M., Canitano, R., ... Tordjman, S. (2019). Exploring self-consciousness from self-and other-image recognition in the mirror: Concepts and evaluation. Frontiers in Psychology, 10, 719. https://doi. org/10.3389/fpsyg.2019.00719

[79] Bolis, D., \& Schilbach, L. (2020). 'I interact therefore I am': The self as a historical product of dialectical attunement. Topoi, 39(3), 521-534. https://doi.org/10.1007/s11245-018-9574-0

[80] Schmaltz, R. M., Jansen, E., \& Wenckowski, N. (2017). Redefining critical thinking: Teaching students to think like scientists. Frontiers in Psychology, 8, 459. https://doi.org/10.3389/ fpsyg.2017.00459

[81] Boekaerts, M., Zeidner, M., \& Pintrich, P. R. (Eds.). (1999). Handbook of self-regulation. Elsevier. https://doi.org/10.1016/B978-012109890-2/50030-5

[82] Thompson, R. A. (1994). Emotion regulation: A theme in search of definition. Monographs of the Society for Research in Child Development, 59(2-3), 25-52. https://doi. org/10.1111/j.1540-5834.1994.tb01276.x; https://doi.org/10.2307/1166137

[83] Sarzotti, F. (2018). Self-monitoring of emotions and mood using a tangible approach. Computers, 7(1), 7. https://doi.org/10.3390/computers7010007

[84] Diamond, A. (2013). Executive functions. Annual Review of Psychology, 64, 135-168. https://doi.org/10.1146/annurev-psych-113011-143750

[85] Lapate, R. C., Rokers, B., Tromp, D. P. M., Orfali, N. S., Oler, J. A., Doran, S. T., ... Davidson, R. J. (2016). Awareness of emotional stimuli determines the behavioral consequences of amygdala activation and amygdala-prefrontal connectivity. Scientific Reports, 6(1), 1-16. https://doi.org/10.1038/srep25826

[86] Tang, Y. Y., \& Posner, M. I. (2009). Attention training and attention state training. Trends in Cognitive Sciences, 13(5), 222-227. https://doi.org/10.1016/j.tics.2009.01.009

[87] Thibaut, A., Schiff, N., Giacino, J., Laureys, S., \& Gosseries, O. (2019). Therapeutic interventions in patients with prolonged disorders of consciousness. The Lancet Neurology, 18(6), 600-614. https://doi.org/10.1016/S1474-4422(19)30031-6

[88] Dresler, M., Sandberg, A., Ohla, K., Bublitz, C., Trenado, C., Mroczko-Wąsowicz, A., ... Repantis, D. (2013). Non-pharmacological cognitive enhancement. Neuropharmacology, 64, 529-543. https://doi.org/10.1016/j.neuropharm.2012.07.002

[89] Krause, E. D., Mendelson, T., \& Lynch, T. R. (2003). Childhood emotional invalidation and adult psychological distress: The mediating role of emotional inhibition. Child Abuse \& Neglect, 27(2), 199-213. https://doi.org/10.1016/S0145-2134(02)00536-7

[90] Low, R. S., Overall, N. C., Hammond, M. D., \& Girme, Y. U. (2017). Emotional suppression during personal goal pursuit impedes goal strivings and achievement. Emotion, 17(2), 208. https://doi.org/10.1037/emo0000218

[91] Krishnakumar, D., Hamblin, M. R., \& Lakshmanan, S. (2015). Meditation and yoga can modulate brain mechanisms that affect behavior and anxiety-A modern scientific perspective. Ancient Science, 2(1), 13. https://doi.org/10.14259/as.v2i1.171 
[92] Sadri, A., \& Janani, H. (2015). Relationship of emotional intelligence and self-regulation of male elite swimmers. Annals of Applied Sport Science, 3(4), 9-18. https://doi. org/10.18869/acadpub.aassjournal.3.4.9

[93] Koole, S. L., Van Dillen, L. F., \& Sheppes, G. (2011). The self-regulation of emotion. Handbook of Self-regulation: Research, Theory, and Applications, 2, 22-40.

[94] Salem, R. (2003). Empathic listening. Beyond intractability.

[95] Dores, A. R., Martins, H., Reis, A. C., \& Carvalho, I. P. (2021, May). Empathy and coping in allied health sciences: Gender patterns. In Healthcare (Vol. 9, No. 5, p. 497). Multidisciplinary Digital Publishing Institute. https://doi.org/10.3390/healthcare9050497

[96] Morgan, T. (2018). Laland, Kevin. 2017. Darwin's unfinished symphony: How culture made the human mind. Evolutionary Studies in Imaginative Culture, 2(1), 121-124.

[97] Gold, J. M. (2013). Spirituality and self-actualization: Considerations for 21st-century counselors. The Journal of Humanistic Counseling, 52(2), 223-234. https://doi.org/ 10.1002/j.2161-1939.2013.00044.x

[98] Tugade, M. M., \& Fredrickson, B. L. (2007). Regulation of positive emotions: Emotion regulation strategies that promote resilience. Journal of Happiness Studies, 8(3), 311-333. https://doi.org/10.1007/s10902-006-9015-4

[99] Wayment, H. A., \& Bauer, J. J. (2018). The quiet ego: Motives for self-other balance and growth in relation to well-being. Journal of Happiness Studies, 19(3), 881-896. https://doi. org/10.1007/s10902-017-9848-Z

[100] Wong, P. T. (2016a). Self-transcendence: A paradoxical way to become your best. International Journal of Existential Psychology and Psychotherapy, 6(1), 9.

[101] Frank1, V. E. (1966). Self-transcendence as a human phenomenon. Journal of Humanistic Psychology, 6(2), 97-106. https://doi.org/10.1177/002216786600600201

[102] Daaleman, T. P., Cobb, A. K., \& Frey, B. B. (2001). Spirituality and well-being: An exploratory study of the patient perspective. Social Science \& Medicine, 53(11), 1503-1511. https://doi.org/10.1016/S0277-9536(00)00439-1

[103] Thomas, J. C., Burton, M., Quinn Griffin, M. T., \& Fitzpatrick, J. J. (2010). Selftranscendence, spiritual well-being, and spiritual practices of women with breast cancer. Journal of Holistic Nursing, 28(2), 115-122. https://doi.org/10.1177/0898010109358766

[104] Liu, P., Wang, X., Li, D., Zhang, R., Li, H., \& Han, J. (2021). The benefits of self-transcendence: Examining the role of values on mental health among adolescents across regions in China. Frontiers in Psychology, 12, 243. https://doi.org/10.3389/ fpsyg.2021.630420

[105] Heerwagen, J. (2009). Biophilia, health, and well-being. Restorative commons: creating health and well-being through urban landscapes, USDA Forest Service, Pennsylvania, 39-57.

[106] Charoensukmongkol, P. (2014). Benefits of mindfulness meditation on emotional intelligence, general self-efficacy, and perceived stress: Evidence from Thailand. Journal of Spirituality in Mental Health, 16(3), 171-192. https://doi.org/10.1080/19349637.2014.925364

[107] Conversano, C., Di Giuseppe, M., Miccoli, M., Ciacchini, R., Gemignani, A., \& Orrù, G. (2020). Mindfulness, age and gender as protective factors against psychological distress during Covid-19 pandemic. Frontiers in Psychology, 11, 1900. https://doi.org/10.3389/ fpsyg. 2020.01900

[108] Kabat-Zinn, J. (2015). Mindfulness. Mindfulness, 6(6), 1481-1483. https://doi.org/10.1007/ s12671-015-0456-X

[109] Shapiro, S. L., Carlson, L. E., Astin, J. A., \& Freedman, B. (2006). Mechanisms of mindfulness. Journal of Clinical Psychology, 62(3), 373-386. https://doi.org/10.1002/jclp.20237

[110] Tang, Y. Y., Hölzel, B. K., \& Posner, M. I. (2015). The neuroscience of mindfulness meditation. Nature Reviews Neuroscience, 16(4), 213-225. https://doi.org/10.1038/nrn3916 
[111] D'Amico, A. (2018). The use of technology in the promotion of children's emotional intelligence: The multimedia program "Developing emotional intelligence". International Journal of Emotional Education, 10(1), 47-67.

[112] Serrat, O. (2017). Understanding and developing emotional intelligence. In Knowledge solutions (pp. 329-339). Springer, Singapore. https://doi.org/10.1007/978-981-10-0983-9_37

[113] Bargh, J. A., \& Chartrand, T. L. (1999). The unbearable automaticity of being. American Psychologist, 54(7), 462. https://doi.org/10.1037/0003-066X.54.7.462

[114] Drigas, A., \& Mitsea, E. (2020). A metacognition based 8 pillars mindfulness model and training strategies. International Journal of Recent Contributions from Engineering, Science \& IT (iJES), 8(4), 4-17. https://doi.org/10.3991/ijes.v8i4.17419

[115] Lawson, G. M., McKenzie, M. E., Becker, K. D., Selby, L., \& Hoover, S. A. (2019). The core components of evidence-based social emotional learning programs. Prevention Science, 20(4), 457-467. https://doi.org/10.1007/s11121-018-0953-y

[116] Drigas, A., \& Papoutsi, C. (2019). Emotional intelligence as an important asset for HR in organizations: Leaders and employees. International Journal of Advanced Corporate Learning, 12(1). https://doi.org/10.3991/ijac.v12i1.9637

[117] Sternberg, R. J. (2001). Metacognition, abilities, and developing expertise: What makes an expert student? In Metacognition in learning and instruction (pp. 247-260). Springer, Dordrecht. https://doi.org/10.1007/978-94-017-2243-8 12

[118] Mitsea, E., \& Drigas, A. (2019). A journey into the metacognitive learning strategies. International Journal of Online \& Biomedical Engineering, 15(14). https://doi.org/ $\underline{10.3991 / \text { ijoe.v15i14.11379 }}$

\section{Authors}

Athanasios Drigas is a Research Director at IIT-N.C.S.R. 'Demokritos', Institute of Informatics and Telecommunications - Net Media Lab \& Mind - Brain R \& D, Agia Paraskevi, 15310, Athens, Greece (dr@iit.demokritos.gr).

Chara Papoutsi is a Phd candidate in Information and Communication Systems Engineering Department at the University of the Aegean. She is also with N.C.S.R. Demokritos, Institute of Informatics and Telecommunications, Net Media Lab, Athens (papoutsi.xara@yahoo.com).

Charalabos Skianis is Vice Rector Finance, Planning \& Development at University of the Aegean and a Professor in the Department of Information and Communication Systems Engineering at the University of the Aegean, Greece (cskianis@,aegean.gr).

Article submitted 2021-08-11. Resubmitted 2021-10-15. Final acceptance 2021-10-16. Final version published as submitted by the authors. 